\title{
A Visão Jurídica do Uso do Medicamento off label no âmbito da Saúde Suplementar
}

The Legal View of the Use of the off-label Drug in the scope of Supplementary Health

La Visión Jurídica del Uso del Medicamento off label en el ámbito de la Salud Suplementaria

Marilusa Cunha da Silveira ${ }^{1}$

RESUMO: Objetivo: Este artigo tem o objetivo analisar do ponto de vista sobre o tema do uso do medicamento off label no âmbito da Saúde Suplementar. Medotologia: foi realizado uma revisão da legislação pátria, consultando o inteiro teor das leis e normas que constituem o tema. Foram consultadas as bases de dados legislativos do Senado Federal, bem como a base legal da Agência Nacional de Vigilância Sanitária e a Agência Nacional de Saúde Suplementar. Resultados: há fartura de normas legais para a regulamentação da matéria, sendo que toda a política de tratamento deste tema está consubstanciada na base da pirâmide hierárquica de leis, ou seja, nas portarias e instruções normativas. Conclusão: A existência de previsão de cobertura da doença ou patologia no contrato, há liberdade de prescrição de medicamentos off label pelo médico assistente se aplica.

Palavras-chave: Saúde Suplementar. Direito à Saúde. Preparações Farmacêuticas.

ABSTRACT: Objective: This article aims to analyze from the point of view on the subject of the use of the off label drug in the scope of Supplementary Health. Methods: a review of the national legislation has been carried out, consulting the entire content of the laws and norms that constitute the theme. The legislative databases of the Federal Senate were consulted, as well as the legal basis of the National Sanitary Surveillance Agency and the National Supplementary Health Agency. Results: There are plenty of legal norms for the regulation of the matter, and the whole treatment policy of this theme is based on the hierarchical pyramid of laws, that is, in ordinances and normative instructions. Conclusion: The existence of predicted coverage of the disease or pathology in the contract, there is freedom of prescription of off-label medications by the attending physician applies.

Keywords: Suplementary Health. Right of Health. Pharmaceutical Preparations

RESUMEN: Objetivo: Este artículo tiene el objetivo de analizar desde el punto de vista sobre el tema del uso del medicamento off label en el ámbito de la Salud Suplementaria. Medotología: se realizó una revisión de la legislación patria, consultando el entero contenido de las leyes y normas que constituyen el tema. Se consultaron las bases de datos legislativos del Senado Federal, así como la base legal de la Agencia Nacional de Vigilancia Sanitaria y la Agencia Nacional de Salud Suplementaria. Resultados: hay abundancia de normas legales para la reglamentación de la materia, siendo que toda la política de tratamiento de este tema está consubstanciada en la base de la pirámide jerárquica de leyes, o sea, en las

\footnotetext{
${ }^{1}$ Mestranda em Desenvolvimento e Políticas Públicas pela Escola Nacional de Saúde Pública Sergio Arouca,
} Contadora e Analista de Gestão em Saúde da Fundação Oswaldo Cruz. E-mail: marilusa.silveira@fiocruz.br. 
ordenanzas e instrucciones normativas. Conclusión: La existencia de previsión de cobertura de la enfermedad o patología en el contrato, hay libertad de prescripción de medicamentos fuera de etiqueta por el médico asistente se aplica.

Palabras-Ilave: Salud Suplementaria. Derecho a la Salud. Preparación Farmacéuticas

\section{Introdução}

O artigo trata da análise legal e normativa da possibilidade da prescrição de medicamento off label no âmbito da saúde suplementar. É um tema bastante caro para aqueles que estudam o Direito Sanitário, posto que no âmbito da assistência á saúde pública, tal uso se dá apenas com ordem judicial. A temática fez nascer a curiosidade de um estudo mais profundo da legislação, a fim de conhecer, se a saúde suplementar, por suas atribuições e características autoriza a prescrição desse uso não registrado para certos medicamentos.

\section{O Direito à Saúde no Brasil}

A Constituição da República, em seu art. $1^{\circ}$ inciso III traz dentre seus princípios fundamentais o da dignidade da pessoa (1), o que faz da vida um dos valores máximos da nossa ordem jurídica. No consequente, tudo o que é relacionado à vida, como expressão da dignidade da pessoa, recebe proteção de modo pleno e na forma de prestações positivas por parte do Estado.

Pela magnitude axiológica do direito à vida e na perspectiva das ações e políticas positivas em favor da sua garantia, o legislador constitucional sediou o direito à saúde dentre os direitos sociais com status de garantia fundamental.

Nessa condição, o direito à saúde assume a primazia e preferência na ordem jurídica em face de outros direitos, mesmo que sediados no próprio texto da Lei Maior.

Daí porque, nessa linha de valoração de direitos, a Constituição da República orientou o direito à saúde sob a égide dos princípios da universalidade, integralidade e equidade, mediante a garantia de acesso do cidadão às ações e aos serviços para promoção, proteção e recuperação da saúde (1).

A abrangência ditada pela norma constitucional de integralidade e de universalidade traz como objeto de alcance a garantia do direito à saúde e a assistência farmacêutica (1). 
Vê-se, portanto, que a dimensão protetiva e positiva do direito à saúde é ampla e abrangente, justamente para dar azo à integralidade, universalidade e equidade como estruturantes e norte operacional e executivo das ações e políticas neste campo.

Importante observar, entretanto, que estes princípios e ditames não estão dirigidos apenas para o Estado e a Sociedade, mas também a todos os atores privados que atuam no campo da saúde, independentemente do tipo de atividade específica.

Isto porque a Constituição da República adotou a livre iniciativa como fundamento da República Federativa do Brasil, elencando-a, de igual forma, como fundamento da ordem econômica nacional. É o que se afere nos artigos $1^{\circ}$, IV e 170 , caput, do texto constitucional (1).

A adoção de sistema fundado na livre iniciativa não relegou o Estado ao papel de mero observador das atividades dos particulares. Prevendo a eventual necessidade de disciplinar a exploração de empreendimentos privados, o parágrafo único do artigo 170 da CF/88 permitiu ao Poder Público, nos casos previstos em lei, inclusive, conforme a hipótese, condicionar o desempenho de determinadas atividades à autorização prévia do Estado²

Fica claro assim, que em nossa ordem constitucional, especialmente no campo das garantias fundamentais, a liberdade de iniciativa é uma liberdade relativa e potencialmente normatizada (libertas secundum legem). Daí que não se pode confundir livre iniciativa com princípios exclusivamente de mercado, mas, ao reverso, reafirme-se, a prioridade e supremacia é do bem maior guarnecido, que no nosso caso é a saúde.

É, pois, sob o contexto constitucional delineado que deve ser encarada a garantia constitucional do direito à saúde, com a necessária previsão da assistência farmacêutica, e, para ser mais específico na matéria aqui em discussão, do uso off label de medicamentos.

\section{O registro do medicamento no Brasil}

No contexto da garantia social do direito à saúde é que se insere a questão específica dos medicamentos, seja no que tange à assistência farmacêutica ou seja no que toca à própria possibilidade de serem produzidos e colocados para consumo.

Nesse diapasão, é possível asseverar que a Lei no 6.360/76 (2) foi recepcionada pela ordem constitucional de 1988 como principal baliza regulatória do mercado de

\footnotetext{
${ }^{2}$ Exemplo claro é o registro de medicamentos, segundo a Lei 6.360 de 1976 (3)
} 
medicamentos e de outros produtos submetidos ao chamado regime jurídico-administrativo da vigilância sanitária. E, segundo seu artigo 12, os produtos nele previstos apenas podem ser introduzidos no mercado após seu registro junto ao Ministério da Saúde ${ }^{3}$ (3).

Particularmente, no que pertine aos medicamentos, o artigo 16, II, da citada lei, condiciona seu registro, dentre outros requisitos, à demonstração científica da segurança e eficácia de seu uso proposto, como visto na transcrição adiante trazida:

Art. 16. O registro de drogas, medicamentos, insumos farmacêuticos e correlatos, dadas as suas características sanitárias, medicamentosas ou profiláticas, curativas, paliativas, ou mesmo para fins de diagnóstico, fica sujeito, além do atendimento das exigências próprias, aos seguintes requisitos específicos: (...)

II - que o produto, através de comprovação científica e de análise, seja reconhecido como seguro e eficaz para o uso a que se propõe, e possua a identidade, atividade, qualidade, pureza e inocuidade necessárias;

A competência para a concessão de registro de medicamentos foi transferida à Agência Nacional de Vigilância Sanitária - ANVISA, autarquia em regime especial que também recebeu competência normativa para regulamentar os requisitos técnicos necessários para a proteção da saúde pública no país (3).

Art. $7^{\circ}$ Compete à Agência proceder à implementação e à execução do disposto nos incisos II a VII do art. $2^{\circ}$ desta Lei, devendo: (...)

III - estabelecer normas, propor, acompanhar e executar as políticas, as diretrizes e as ações de vigilância sanitária; (...)

IX - conceder registros de produtos, segundo as normas de sua área de atuação;

Art. 80 Incumbe à Agência, respeitada a legislação em vigor, regulamentar, controlar e fiscalizar os produtos e serviços que envolvam risco à saúde pública.

$\S 1^{\circ}$ Consideram-se bens e produtos submetidos ao controle e fiscalização sanitária pela Agência:

I - medicamentos de uso humano, suas substâncias ativas e demais insumos, processos e tecnologias;

Diante dos argumentos expostos, é possível concluir que o comércio de medicamentos no Brasil é atividade econômica regulada pelo Estado, sendo seu exercício condicionado à autorização prévia do Poder Público, denominada no país de registro. O registro equivale, nesse sentido, à autorização administrativa de introdução ao mercado, e se encontra

\footnotetext{
${ }^{3}$ Competência transferida para a Agência Nacional de Vigilância Sanitária pela Lei oㅜ 9.782/99
} 
precipuamente vinculado à demonstração científica da segurança e eficácia do medicamento em questão.

Assim, temos que o regime ordinário adotado no Brasil para medicamentos de uso humano é caracterizado pelo estabelecimento legal de competência administrativa para a autorização prévia de sua introdução no mercado, ficando igualmente estabelecida a competência regulamentar da Administração Pública para estabelecer os critérios técnicos para a aferição da segurança e eficácia dos produtos em questão.

Confira-se neste sentido, à guisa de exemplo e por correlação mais frequente com o uso off label de medicamentos, as exigências trazidas pela RDC de ํo 60, de 2014 (4), no que tange às condições e requisitos para aprovação, de produtos sintéticos, de medicamento novo ou nova indicação terapêutica de medicamento já registrado, in verbis:

Art. 23. Esta seção se refere ao registro de medicamento com IFA não registrado no país, seus novos sais, isômeros ou mistura de isômeros, ésteres, éteres, complexos ou demais derivados, igualmente não registrados.

Art. 24. A petição de registro descrita nesta seção, além da documentação citada nas Seções III e IV do Capítulo III, deverá estar acompanhada de:

I - relatório de segurança e eficácia de acordo com guia específico, contendo:

a) relatório de ensaios não-clínicos; e

b) relatório de ensaios clínicos fase I, II e III.

II - plano de Farmacovigilância, de acordo com a legislação específica vigente.

$\S 1^{\circ}$ Em situações específicas relacionadas à segurança, um Plano de Minimização de Risco poderá ser exigido de forma adicional ao Plano de Farmacovigilância disposto no inciso II."

.Art. 35. Esta seção se refere ao registro de nova indicação terapêutica no país, para um medicamento já registrado na mesma forma farmacêutica e mesma concentração.

Art. 36. A petição de registro descrita nesta seção, além da documentação citada nas Seções III e IV do Capítulo III, deverá estar acompanhada de:

I - justificativa técnica para o registro;

II - relatório de segurança e eficácia de acordo com o guia específico, contendo os resultados de estudos clínicos de fase III e fase I e II , se aplicável; e.

III - plano de Farmacovigilância adequado à nova indicação terapêutica, de acordo com a legislação específica vigente. 
Note-se a centralidade da regra na questão da segurança e eficácia, já que nestes dois fatores é que se concentram a primazia da atividade sanitária em matéria de medicamentos, tanto no pré quanto no pós registro.

No mesmo diapasão, a norma que cuida do registro de medicamentos biológicos RDC de $n^{\circ}$ 55, de 2010 (4), que expressamente dispõe, in verbis:

Art. 18. Todas as indicações terapêuticas solicitadas no registro, para o produto biológico novo ou produto biológico, devem estar documentalmente demonstradas nos relatórios dos estudos clínicos apensados ao dossiê de registro do produto, conforme estabelecido nesta Resolução.

Assim é porque as indicações terapêuticas são absolutamente cruciais, condicionando não apenas a realização dos estudos clínicos do produto, mas também o controle do respectivo uso na fármacovigilância, haja vista que os fármacos são aprovados segundo o perfil de benefício/risco que apresentam para tratamento de patologias específicas, bem definidas e - segundo os estudos conduzidos - apenas para estas.

Pode-se dizer que o registro de medicamento representa a atuação administrativa e técnica de um ente público com competência específica para tal autorização, e, é um ato administrativo vinculado ao conteúdo técnico/científico submetido para exame do agente sanitário, de modo que ao final da análise do dossiê técnico de registro ou pós-registro, conforme o caso, a utilização do medicamento fica adstrita às conclusões e delimitações que são representadas pelas indicações constantes da respectiva bula ( "label"), segundo consta da RDC de ํㅜ 47, de 2009 (5).

\section{Uso de Medicamentos off label - conceito e visão geral}

Cada medicamento registrado no país recebe a aprovação da ANVISA para uma ou mais indicações, as quais precisam ser comprovadas por meio da apresentação de estudos clínicos robustos e confiáveis. A partir de sua aprovação pelo órgão sanitário, a indicação do medicamento passa a constar em sua bula, sendo aquela respaldada pela Agência e a que atende ao determinado no art. 12, da Lei no 6.360, de 1976 (2)

O uso off label não tem regulamentação específica no Brasil, mas decorre de prerrogativas do médico assistente, conforme previsão do Código de Ética Médica (6), do Conselho Federal de Medicina - CRM, in verbis: 
Art. 32. Deixar de usar todos os meios disponíveis de diagnóstico e tratamento, cientificamente reconhecidos e a seu alcance, em favor do paciente.

Pela distribuição de competências operada pela ordem jurídica, não cabe a ANVISA regular a atividade dos médicos, cabendo a este decidir o que é mais adequado para o seu paciente tendo em conta todas as circunstâncias do caso concreto.

Neste sentido o Parecer CFM de ํㅜ5, de 2016 (7), in verbis:

O Parecer CFM no 2/2016 determina que os procedimentos médicos off-label são aqueles em que se utilizam materiais ou fármacos fora das indicações em bula ou protocolos e sua indicação e prescrição são de responsabilidade do médico'. Isso significa que o médico que os prescreve assume a incumbência pelos possíveis riscos dessa conduta. O paciente deve ser informado e deve dar o seu consentimento livre e esclarecido.

As hipóteses mais comuns que podem ser tomadas como off label possuem algumas das seguintes circunstâncias, basicamente previstas na RDC de nํ09, de 2015 (8), no Parágrafo Único do art. $2^{\circ}$, in verbis:

[...] possui indicações diferentes daquelas que constam na bula do medicamento;

- usado em posologias não comuns;

- a via de administração do medicamento é diferente da preconizada;

- a administração ocorre em faixas etárias para as quais o medicamento não foi testado;

- a administração do medicamento é feita para tratamento de doenças que não foram estudadas;

- indicação terapêutica é diferente da aprovada para o medicamento;

- administração de formulações extemporâneas ou de doses elaboradas a partir de especialidades farmacêuticas registradas;

- uso de medicamentos importados e substâncias químicas sem grau farmacêutico.

Havendo uma ou mais das características acima na prescrição médica a mesma estará enquadra dentro do conceito de medicamento off label.

Interessante conferir a manifestação da Agência acerca do tema, segundo se extrai do comunicado obtido por comunicação no Portal ANVISA (9):

Cada medicamento registrado no Brasil recebe aprovação da Anvisa para uma ou mais indicações, as quais passam a constar na sua bula, e que são as respaldadas pela Agência. O registro de medicamentos novos é concedido desde que sejam comprovadas a qualidade, a eficácia e a segurança do medicamento, sendo as duas últimas baseadas na avaliação de estudos clínicos realizados para testá-lo para essas indicações. 
Quando um medicamento é aprovado para uma determinada indicação isso não implica que esta seja a única possível, e que o medicamento só possa ser usado para ela. Outras indicações podem estar sendo, ou vir a ser estudadas, as quais, submetidas à Anvisa quando terminados os estudos, poderão vir ser aprovadas e passar a constar da bula. Estudos concluídos ou realizados após a aprovação inicial podem, por exemplo, ampliar o uso do medicamento para outra faixa etária, para uma fase diferente da mesma doença para a qual a indicação foi aprovada, ou para uma outra doença, assim como o uso pode se tornar mais restrito do que inicialmente se aprovou.

Uma vez comercializado o medicamento, enquanto as novas indicações não são aprovadas, seja porque as evidências para tal ainda não estão completas, ou porque a agência reguladora ainda as está avaliando, é possível que um médico já queira prescrever o medicamento para um seu paciente que tenha uma delas. Podem também ocorrer situações de um médico querer tratar pacientes que tenham uma certa condição que, por analogia com outra semelhante, ou por base fisiopatológica, ele acredite possam vir a se beneficiar de um determinado medicamento não aprovado para ela.

Quando o medicamento é empregado nas situações descritas acima está caracterizado o uso off label do medicamento, ou seja, o uso não aprovado, que não consta da bula. O uso off label de um medicamento é feito por conta e risco do médico que o prescreve, e pode eventualmente vir a caracterizar um erro médico, mas em grande parte das vezes trata-se de uso essencialmente correto, apenas ainda não aprovado. Há casos mesmo em que esta indicação nunca será aprovada por uma agência reguladora, como em doenças raras cujo tratamento medicamentoso só é respaldado por séries de casos. Tais indicações possivelmente nunca constarão da bula do medicamento porque jamais serão estudadas por ensaios clínicos ${ }^{4}$.

O que é uso off label hoje pode vir a ser uso aprovado amanhã, mas nem sempre isso ocorrerá. O que é off label hoje, no Brasil, pode já ser uso aprovado em outro país. Não necessariamente o medicamento virá a ser aprovado aqui, embora frequentemente isso vá ocorrer, já que os critérios de aprovação estão cada vez mais harmonizados internacionalmente.

A aprovação no Brasil, porém, pode demorar, por vários motivos, entre os quais o de que o pedido de registro pode ser feito muito mais tarde aqui do que em outros países. Também pode ocorrer que o medicamento receba aprovação acelerada em outro país, baseada na apresentação de estudos preliminares ou incompletos, o que, via de regra, não é aceito pela Anvisa. Por fim, um uso autorizado no Brasil pode ser uso off label em outros países. A classificação de uma indicação como off label pode, pois, variar temporalmente e de lugar para lugar. O uso off label é, por definição, não autorizado por uma agência reguladora, mas isso não implica que seja incorreto.

Como se vê, o uso off label de medicamentos não pode ser considerado ilegal, e muitas vezes pode ser até clinicamente apropriado, especialmente naqueles situações limites, nas

\footnotetext{
${ }^{4}$ Esta situação é comum na hipótese de raridade da doença, com pequena quantidade de pacientes por ela acometidos e que, por isto, impossibilita a condução de estudo clínico sustentável.
} 
quais foram tentadas várias alternativas terapêuticas sem sucesso e para as quais o médico assistente pode visualizar potenciais benefícios que superem os riscos do uso de medicamento sem conclusão de segurança e eficácia para o fim que se está indicando.

Lado outro, uso off label está intimamente ligado a uma série de questões clínicas, de segurança e ética em relação à quais os médicos prescritores devem estar atentos, uma vez que, inobstante tenham a prerrogativa da prescrição, devem prescrever do modo mais seguro possível, com fundamento nas melhores evidências científicas disponíveis (9)

\section{O Uso Off Label e a Saúde Suplementar - Lei no 9.656, de 1998}

A inexistência de uma definição e regulamentação jurídico-legal da figura do uso off label de medicamento gera na realidade brasileira a necessidade de intervenção do Poder Judiciário como definidor e norteador dos contornos do que sejam direitos e obrigações nesta área de discussão do direito à saúde.

Neste giro, pergunta-se: há obrigatoriedade da operadora de plano ou seguro de saúde cobrir os custos da opção terapêutica do médico assistente pela via do medicamento off label?.

A Lei no 9.656, de 1998 (10), aponta as hipóteses de exclusão de cobertura para tratamento clínico ou cirúrgico experimental, como se constata pelo o art. 10:
É instituído o plano-referência de assistência à saúde, com cobertura assistencial médico-ambulatorial e hospitalar, compreendendo partos e tratamentos, realizados exclusivamente no Brasil, com padrão de enfermaria, centro de terapia intensiva, ou similar, quando necessária a internação hospitalar, das doenças listadas na Classificação Estatística Internacional de Doenças e Problemas Relacionados com a Saúde, da Organização Mundial de Saúde, respeitadas as exigências mínimas estabelecidas no art. 12 desta Lei, exceto:
I - tratamento clínico ou cirúrgico experimental;
$\S 1^{\circ}$ - As exceções constantes dos incisos deste artigo serão objeto de regulamentação pela ANS. “

Note-se que a norma em espécie cita o tratamento experimental, o que remonta à questão anteriormente tratada no que tange à diferenciação entre medicamento off label e medicamento experimental.

Neste sentido, como visto pelas referências a Lei no 9.656/98 (10), inexiste na mesma qualquer menção sobre o uso off label de medicamentos, havendo a possibilidade de 
exclusão de cobertura para o fornecimento de medicamentos importados não nacionalizados ${ }^{5}$ e medicamentos para tratamento domiciliar ${ }^{6}$.

No exercício de sua competência institucional e na condição de braço regulamentador do Estado em matéria de saúde suplementar, a Agência Nacional de Saúde Suplementar ANS vem editando Resoluções Normativas em complementariedade e regulamentação da Lei ํㅜ 9.656, de 1998 (10), estando vigente quanto ao Rol de Procedimentos e Eventos em Saúde a Resolução Normativa ํㅜ 387, de 2015 (11).

É nesta regulamentação administrativa que aparece pela primeira vez a menção a medicamento off label, como indicação de possibilidade ${ }^{7}$ de exclusão de cobertura.

Note-se que a norma em referência - RN no 387, de 2015 (11), não conceitua ou disciplina o medicamento ou uso off label ${ }^{8}$, mas apenas faz menção à hipótese.

Assim reza o art. 20, da RN oㅜ 387, de 2015 (11), in verbis:

A cobertura assistencial de que trata o plano-referência compreende todos os procedimentos clínicos, cirúrgicos, obstétricos e os atendimentos de urgência e emergência, na forma estabelecida no artigo 10 da Lei no 9.656, de 1998.

$\S 1^{\circ}$ São permitidas as seguintes exclusões assistenciais:

I - tratamento clínico ou cirúrgico experimental, isto é, aquele que:

a) emprega medicamentos, produtos para a saúde ou técnicas não registrados/não regularizados no país;

b) é considerado experimental pelo Conselho Federal de Medicina CFM ou pelo Conselho Federal de Odontologia- CFO; ou

c) não possui as indicações descritas na bula/manual registrado na ANVISA (uso off-label).

Deve ser observado, entretanto, que a autarquia incorre em confusão ao categorizar o uso off label de medicamento como espécie de tratamento clínico experimental.

Porém, possibilidade de atuação privada no campo da assistência à saúde, em sede constitucional, se fez menção a um serviço disponibilizado no mercado, e, portanto, com natureza comercial, a atrair, segundo o entendimento jurisprudencial vigente, a defesa do consumidor.

\footnotetext{
${ }^{5}$ Art. 10 , V, da Lei n ${ }^{2}$ 9.656, de 1998.

${ }^{6}$ Art. $10, \mathrm{VI}$

, da Lei n⿳亠 9.656, de 1998.

7 A exclusão não é cogente, mas possível. A RN no 387, de 2015, diz que é permitida, donde advém a facultatividade de se fazê-lo.

${ }^{8} \mathrm{Nem}$ seria possível haver qualquer regulamentação por parte da ANS sobre uso ou medicamento off label por lhe carecer competência para tanto.
} 
A outra linha de orientação resume-se à existência de previsão de cobertura da doença ou patologia no contrato. Havendo previsão de cobertura para a doença o fundamento de que há liberdade de prescrição pelo médico assistente se aplica.

Decisão bastante elucidativa deste entendimento foi proferida, não de hoje, pelo Superior Tribunal de Justiça - STJ:

A orientação que se vem firmando, e que merece exame da Corte, é sobre esse ponto, considerando a consolidação legislativa vigente com a Lei $n^{0}$ 9.656/98. O que se procurou fazer, pelo menos no meu entender, foi estabelecer critério para proteger o consumidor e ao mesmo tempo assegurar a viabilidade empresarial dos planos privados de saúde. De fato, não se pode negar o direito do contrato de estabelecer que tipo de doença está ao alcance do plano oferecido. Todavia, entendo que deve haver uma distinção entre a patologia alcançada e a terapia. Não me parece razoável que se exclua determinada opção terapêutica se a doença está agasalhada no contrato. Isso quer dizer que se o plano está destinado a cobrir despesas relativas ao tratamento, o que o contrato pode dispor é sobre as patologias cobertas, não sobre o tipo de tratamento para cada patologia alcançada pelo contrato. Na verdade, se não fosse assim, estar-se-ia autorizando que a empresa se substituísse aos médicos na escolha da terapia adequada de acordo com o plano de cobertura do paciente. $E$ isso, pelo menos na minha avaliação, é incongruente com o sistema de assistência à saúde, porquanto quem é senhor do tratamento é o especialista, ou seja, o médico que não pode ser impedido de escolher a alternativa que melhor convém à cura do paciente. Além de representar severo risco para a vida do consumidor. Foi nessa linha que esta Terceira Turma caminhou quando existia limite de internação em unidade de terapia intensiva (REsp 158.728/RJ, da minha relatoria, DJ de 17.05.99), reiterado pela Segunda Seção (REsp 251.024/SP, Relator o Ministro Sálvio de Figueiredo Teixeira, DJ de 04.02.02). Isso quer dizer que o plano de saúde pode estabelecer que doenças estão sendo cobertas, mas não que o tipo de tratamento está alcançado para a respectiva cura. Assim, por exemplo, se está coberta a cirurgia cardíaca, não é possível vedar a utilização de stent, ou, ainda, se está coberta a cirurgia de próstata, não é possível impedir a utilização de esfíncter artificial para controle da micção. O mesmo se diga com relação ao câncer. Se a patologia está coberta, parece-me inviável vedar a quimioterapia pelo simples fato de que a quimioterapia é uma das alternativas possíveis para a cura da doença. Nesse sentido, parece-me que a abusividade da cláusula reside exatamente nesse preciso aspecto, qual seja não pode o paciente, consumidor do plano de saúde, ser impedido de receber tratamento com o método mais moderno do momento em que instalada a doença coberta em razão de cláusula limitativa. É preciso ficar bem claro que o médico, e não o plano de saúde, é responsável pela orientação terapêutica. Entender de modo diverso põe em risco a vida do consumidor.

(Acórdão da 8ª Câmara Cível do Tribunal de Justiça do Paraná, na Apelação Cível 914.535-5) 
Nesta linha de entendimento, os planos de saúde podem estabelecer quais doenças serão cobertas, mas precisam ser claras e objetivas na comunicação e esclarecimento do consumidor, bem assim que não podem limitar o tipo de tratamento a ser ministrado ao paciente.

\section{Conclusão}

O uso off label de medicamentos é complexa, pois envolve, especialmente, questões éticas e sanitárias importantes para a garantia do direito à saúde e vida. Não se trata apenas de visualizar o problema a partir do ponto de vista mercadológico, pois existem outras implicações que precisam ser consideradas, especialmente as éticas e sanitárias.

No entanto, diante da legislação infraconstitucional e infralegal, entendeu-se que os planos e seguros privados de saúde, componentes da Saúde Suplementar podem estabelecer quais doenças serão cobertas e, consequentemente, o tratamento prescrito pelo profissional médico pertencente aos seus quadros.

\section{Referências}

1 - Brasil. Constituição da República Federativa do Brasil de 1988. Brasília: Senado Federal, 2018.

2 - Brasil. Lei 6.360 de 23 de setembro de 1976. Dispõe sobre a Vigilância Sanitária a que ficam sujeitos os Medicamentos, as Drogas, os Insumos Farmacêuticos e Correlatos, Cosméticos, Saneantes e Outros Produtos, e dá outras providências. Disponível em: http://www.planalto.gov.br/ccivil 03/Leis/L6360.htm. Acesso em 6.5.2018.

1. Brasil. Lei 9.782 de 26 de janeiro de 1999. Define o Sistema Nacional de Vigilância Sanitária, cria a Agência Nacional de Vigilância e dá outras providências. Disponível em: http://www.planalto.gov.br/ccivil 03/Leis/L9782.htm. Acesso em 6.5.2018.

2. Agência Nacional de Vigilância Sanitária - Resolução da Diretoria Colegiada - RDC n. 60 de 2014. Disponível em: http://portal.anvisa.gov.br/legislacao. Acesso em 6.5.2018.

3. Agência Nacional de Vigilância Sanitária - Resolução da Diretoria Colegiada - RDC n.55 de 2010. Disponível em: http://portal.anvisa.gov.br/legislacao Acesso em 6.5.2018.

4. Agência Nacional de Vigilância Sanitária - Resolução da Diretoria Colegiada - RDC n.47 de 2009. Disponível em: http://portal.anvisa.gov.br/legislacao. Acesso em 6.5.2018. 
5. Conselho Federal de Medicina. Código de Ética Médica do Brasil. Disponível em: http://www.rcem.cfm.org.br/index.php/cem-atual. Acesso em 5.5.2018.

6. Conselho Federal de Medicina. Parecer CFM n. 55, de 2016. Disponível em. http://portal.cfm.org.br/index.php?option=com normas\&buscaEfetuada=true\&tipoNorma $\mathrm{P}=\mathrm{P} \&$ normasUf $=\mathrm{BR} \&$ normasNumero=\&normasAno=\&normasAssunto=\&normasTexto $=$ \&pagina $=7$. Acesso em 5.5.2018.

7. Agência Nacional de Vigilância Sanitária - Resolução da Diretoria Colegiada - RDC n. 09 de 2015. Disponível em: http://portal.anvisa.gov.br/legislacao. Acesso em 4.5.2018.

8. Agência Nacional de Vigilância Sanitária. Portal oficial disponível em: http://portal.anvisa.gov.br/ Acesso em 4.6.2017.

9. . Brasil. Lei 9.656 de 3 de junho de 1998. Dispõe sobre os planos e seguros privados de assistência à saúde. Disponível em http://www.planalto.gov.br/ccivil 03/leis/L9656compilado.htm. Acesso em 5.5.2018.

10. Agência Nacional de Saúde Suplementar. Resolução Normativa ANS 387 de 2015. Disponível em:

http://www.ans.gov.br/component/legislacao/?view=legislacao\&task=TextoLei\&format=r aw\&id=MzExMA. Acesso em 5.4.2018.

Como citar este artigo:

Silveira MC. A Visão Jurídica do Uso do Medicamento off label no âmbito da Saúde Suplementar. Revista Cadernos Ibero-Americanos de Direito Sanitário. 2018 abr.junr, 7(2):48-60. 